\title{
SENIOR LECTURERS' LEARNING MECHANISMS DURING EMERGENCY REMOTE TEACHING AT BINUS UNIVERSITY
}

\author{
Esti Rahayu ${ }^{1 *}$; Devina ${ }^{2}$ \\ ${ }^{1,2}$ Language Center, Faculty of Humanities, Bina Nusantara University \\ Jl. Kemanggisan Illir III No. 45, Kemanggisan, Palmerah, Jakarta 11480, Indonesia \\ 'estirahayu@gmail.com; 2devina@binus.edu
}

Received: $11^{\text {th }}$ January 2021/ Revised: $27^{\text {th }}$ January 2021/ Accepted: $01^{\text {st }}$ February 2021

How to Cite: Rahayu, E \& Devina. (2021). Senior lecturers' learning mechanisms during emergency remote teaching at Binus University. Humaniora, 12(1), 39-44.

https://doi.org/10.21512/humaniora.v12i1.6906

\begin{abstract}
The research aimed to identify senior lecturers' experiences with online teaching during ERT (Emergency Remote Teaching). The ominous Covid-19 forced tertiary education institutions in Indonesia to employ ERT, both synchronous and asynchronous online teaching, from March 2020. Not all existing lecturers were professionally ready for this change, specifically senior lecturers who had been teaching for more than 25 years. These senior lecturers entered into unfamiliar territory as they had been experiencing the drastic transition to ERT. This transition could be viewed as a learning process as they went through certain learning mechanisms. The qualitative method was used to examine the learning mechanisms of senior lecturers who have been teaching during this ERT. This method was appropriate, as it allowed an understanding of lecturers'experience in their professional growth. This case study examined five senior lecturers who have been teaching English as a Foreign Language at the university level for more than 25 years. Data analysis followed the procedures developed by Braun and Clarke. The research finds that each lecturer experiences learning mechanisms, including identification, coordination, reflection, and transformation. During the identification, they learn to understand the needs to adapt, adopt, and change. They also experience different kinds of unfamiliar events that have to be faced. They adapt to the unfamiliar situation during the phase of coordination through reading, joining webinars (web seminars), and mentoring during the coordination. Each of them reflects on the process of shifting boundaries of their competencies or knowledge from previously teaching offline to online. The last learning mechanism is the transformation that leads to profound changes after experiencing disruptions in the current workflow. Those multiple disruptions shape them in facing ERT.
\end{abstract}

Keywords: senior lecturers, learning mechanism, emergency remote teaching

\section{INTRODUCTION}

Starting from March 2020, all universities in Indonesia were forced to do Emergency Remote Teaching (ERT), whether they were ready or not, including BINUS University. The term ERT suggests that online teaching is considered a temporary solution to an immediate problem (Golden, 2020). It is reported that more than 1,5 billion learners of all ages from around the globe are affected due to school and university closures owing to the Covid-19 (UNESCO, 2020). Considering that education is a fundamental human right in adopting the motto
\#LearningNeverStops, different measures are taken, and solutions are produced immediately to sustain the education system (UNESCO, 2020).

BINUS University had applied various modes of teaching before the pandemic happened by offering face-to-face teaching and guided self-learning classes. However, the threat of Covid-19 has forced BINUS University to decide how to continue teaching and learning while keeping their faculty, staff, and students safe from a public health emergency that is moving fast and not well understood. In the present situation, no matter how clever a solution might be, and some very clever solutions are emerging, many lecturers 
will understandably find this process stressful. This sudden change is easy specifically for senior lecturers who have been teaching for more than 25 years. These lecturers have been through changes since they started teaching 25 years ago. They have experienced utilizing blackboards, using chalks for teaching, learning to use overhead projectors, learning to use PowerPoint presentations, and during the pandemics, they are forced to teach online fully. From March to July 2020, the university conducted ERT, and those senior lecturers had to move to an unfamiliar territory called ERT. It is all conducted online, and it is new for them. Then when the next semester started in September 2020, BINUS adjusted the ERT. First, the asynchronous mode allows students to access course materials at their convenience, have a discussion forum via Learning Management System (LMS) called Binusmaya, where they can access the materials and the assignments. Second, the synchronous mode offers live interaction. This mode is divided into a video conference with the lecturers and Combined Lectures Class (CLC). Video conference is when the students have live interactions with the lecturers. CLC happens when some classes are combined with having a web conference with a lecturer. This CLC class takes up to 400 students in one session. All offered modes allow the students to continue learning, despite the conditions.

As the university moves toward technologydelivered instruction during the pandemics, a major concern about teaching full online is the fear of the technology that does not work in the middle of teaching. This uncertainty has been documented in other studies by Lavine et al. (2012). They have argued that student engagement could be achieved when minimal technical difficulties happen, as it is impossible to expect lecturers to have the technical expertise to be able to provide a smooth technological experience for students in every session. One of the scholars' surveys report shows $77 \%$ of employees are unable to complete online courses in one attempt because of time and connectivity (Batalla-Busquets \& Pacheco-Bernal, 2013). This concern of interruption occurs when both lecturers and students encounter an external event that breaks continuity.

As those senior teachers have to adapt to new situations, they have to move to an unfamiliar territory; from face to face to ERT mode. Many scholars have investigated how people do transition to an unfamiliar area (Fejes \& Köpsén, 2014; Veltman, Van Keulen, \& Voogt, 2019; Fenwick, 2016; Akkerman \& Van Eijck, 2013, and Akkerman \& Bruining, 2016). Some scholars have studied how students move between school and work (Akkerman \& Bakker, 2012; Kersh, 2015), among school and peers (Phelan, Davidson, \& Cao, 1991) or between home and school (Bronkhorst \& Akkerman, 2016; Rosebery et al., 2010). All the findings are related to learning when they move to unfamiliar territory. New ways of teaching are developed, and it indeed produces tensions among lecturers to welcome multi-channel teaching. This can cause frustration, but the subsequent tensions can also lead to new understandings and the development of new and stronger pedagogical practices. Working in a new environment and situation that reflects on the implications of this work on their pedagogy and identity as senior lecturers is likely to be a significant factor in enabling them to learn. Collaboration during this pandemic period provides an opportunity for all participants to work together to gain new knowledge and understandings about teaching and learning, and to develop boundary practices that enhance the learning of teachers, and ultimately the students.

As ERT is enforced, all lecturers have to be familiar with certain technology for instruction. Pamuk (2012) has stated that technology is believed to help teachers develop innovative instructional methods. However, teachers' lacking computer literacy in most countries creates a major barrier in this regard. Studies have shown that teachers do not apply their knowledge of some technology in the classrooms, although many teachers often use technology in their daily lives (Tsai, 2015). Tsai (2015) has also cited that old-aged and senior teachers/lecturers with substantial teaching experience generally show a less positive attitude toward technology. This is shown by their frequency in using computers that are also lesser than the younger lecturers.

Shulman (1987) has stated that teaching is essentially a learned profession. It shows that teaching is something that can be learned. However, the phrase 'learning to teach' gives the perception that it is a direct and easily known process. However, there are no theories of learning to teach that are completely developed (Burns, Freeman, \& Edwards, 2015). Burns, Freeman, and Edwards (2015) have quoted FeimanNemser and Remillard that the phrase 'learning to teach' raises many questions such as what learning to teach brings about, the differences between teacher learning and another learning, who the learners are, and others. By exploring questions about lecturers as learners, teaching is a practice to be learned. It is a multifaceted process that takes place over time in different contexts when the phrase 'learning to teach' can be understood.

When senior teachers move to an unfamiliar territory, learning takes place. Akkerman and Bakker (2012) have identified four learning mechanisms that comprise identification, coordination, reflection, and transformation. Identification is the thinking practice. Fenwick, Edwards, and Sawchuk (2015) have suggested that it is the most critical to all forms of learning and development. Identification is about coming to know what the diverse practices are about in relation to one another (Bakker \& Akkerman, 2017). The next mechanism is coordination that refers to the process of communication to facilitate joint work (Bakker \& Akkerman, 2017). Reflection refers to the process of individuals coming to a better understanding of their practices and others (Bakker \& Akkerman, 2017). The last mechanism is a transformation that serves as the process that leads to meaningful change 
in practice. It often involves some confrontation (Bakker \& Akkerman, 2017).

Those learning mechanisms provide both learning opportunities and serve as a tool for promoting learning (Tuomi-Grohn \& Engestrom, 2003). Fenwick, Edwards, and Sawchuk (2015) have also stated that the learners experience new knowledge construction and transformation, identities, and skills. They enter into a foreign area that is why they question themselves (Gherardi, 2019). Thus, the research aims to identify senior lecturers' experiences with online teaching during ERT. Drawing on the learning mechanism framework by Akkerman and Baker (2017), the research discusses senior lectures' process of learning that support them for ERT. By conducting the research, senior lecturers' voices are heard, and those can help shape future ERT when the pandemic still exists.

\section{METHODS}

Qualitative methods are applied to examine the learning mechanisms of senior lecturers who have been teaching during this ERT. This methodology is appropriate, as it allows an understanding of lecturers' experience in their professional growth. The research examines five senior lecturers who have been teaching English as a Foreign Language at the university level at BINUS University. All participants have been teaching for more than 25 years. During the university closure in the Learning Style Research (LSR) period, they have to use technology as their sole teaching mode for the rest of the semester. The participants are described as Ms. Annie, Ms. Betty, Ms. Chandra, Mr. Dion, and Mr. Emanuel.

Data collection is conducted between April and October 2020 through Zoom. One open-ended question that asks to start the interview is, "Could you share your experience in emergency remote teaching since March?" That one question makes those senior lecturers tell their invaluable stories about their experience, including their joy, sorrow, and lessons. It is digitally recorded and transcribed. Interviews are done twice for each participant. Once the first interview is concluded, the researchers transcribe what has been discussed for further discussion in the second meeting. The second meeting checks whether the transcription from the first interview has matched, clarifies the researchers' understanding, and addresses the first meeting's misrepresentation. Interviews are conducted because participants are able to share their experience of ERT. By doing the interview, the researchers could see their perspectives up close.

Data analysis follows the procedures developed by Braun and Clarke (2012) in their process of analyzing and interpreting themes using the lens of Akkerman's learning mechanisms. This thematic analysis is chosen due to its flexibility: a recursive process in which the researcher can move between stages of analysis if necessary. By doing this, it allows for 'holistic' responses, various interpretations of the participants' perspectives, and more indepth exploration of insiders' understandings of the investigated phenomenon (Miles, Huberman, \& Saldana, 2014).

The first stage is familiarizing with the data by listening to the recording and taking notes on some important topics before transcribing the whole interview. Once the interviews are transcribed, triangulation is conducted by double-checking with the co-researcher that also makes her own transcript. Then, both researchers sit together to agree with the final transcription. Before going to the second phase, the researchers go for member checking by asking the senior lecturers to read the transcript and verify it. The second stage is generating initial codes. The final transcriptions with participants' verification are used for coding the four learning mechanisms. Each researcher identifies which lecturers' words belong to the mechanisms. The third stage is discussing the mechanisms and what lecturers say that both lecturers have matched their coding. The fourth stage is reviewing and refining the themes discovered in stage three. The fifth stage is continuing to review the data associated with each. The codebook is developed from the generated themes, including the themes, definitions of the themes, and the participants' utterances. The researchers invite three raters to estimate the raters' level of chance agreement towards the analyzed themes. The results are compared, then calculated two indices of interrater reliability: the percentage agreement and Cohen's Kappa (1960). The Cohen's Kappa value of $0,76(\mathrm{~K}=0,76)$ indicates a strong level of agreement (McHugh, 2012). Therefore, the results of Kohen's Kappa ascertain that the analysis effectively reflects the participants' data. The sixth stage extends beyond organizing and interpreting themes. From the explanation, triangulation is conducted through another researcher, member checking, and using interrater.

\section{RESULTS AND DISCUSSIONS}

As it is mentioned in the previous section, the results are presented based on the learning mechanisms. The following four paragraphs discuss each learning mechanism. On each learning mechanism, senior lecturers' answers are quoted and discussed.

Identification is about coming to know what the diverse practices are about with one another (Bakker \& Akkerman, 2017). When the BINUS University announces the ERT, five senior lecturers struggle to join the online teaching training. She realizes that the pace of the training is too fast for them. They could not ask the trainer to slow down because they know it would impact the whole training participants. Mr. Emanuel does not feel that the initial training is fast because he has read the training materials before joining the virtual training. He prints all materials, learns them one by one rigorously, so he does not find any difficulties during the session. However, when the 
session is expanded, explaining something beyond the materials, he gets confused. Ms. Betty has stated that she realizes everyone should be able to teach online because of the pandemic, and she is eager to learn. Ms. Chandra has mentioned that online teaching is a new 'game' since it is new for her. Ms. Anie is reluctant initially. She still believes that face-to-face is the best learning mode because lecturers can get instant feedback from students. She points out that body language is important during interactions with students. Those kinds of interactions are absent with the camera. She could not think of interaction virtually. Mr. Dion has accepted the fact that he has to follow the flow, but he also understands his limitations. He trusts that there would be a way to learn.

Coordination is a process that bridges practices. All participants join the initial training provided by the university to understand the gist of online teaching. All of them admit that they ask help from others after the training. Ms. Annie gets support from her daughters during the virtual training, after the training when she needs to do it by herself. Ms. Betty contacts the subject coordinator when she finds difficulties. Luckily, the coordinator is helpful enough for taking her random calls about teaching virtually. Ms. Chandra joins more webinars (web seminar) on online teaching from certain English teaching associations. Those webinars provide a lot of useful teaching tools that can be applied in his class. Mr. Dion and Mr. Emanuel both seek help from the subject coordinator and their sons/daughters. Mr. Dion has mentioned that the subject coordinator is helpful in assisting him when he finds difficulties. Ms. Emmanuel adds that he asks his fellow lecturers when he finds problems with technology. The additional webinars, assistance from their children, colleagues, and their subject coordinator are part of their learning support mechanisms. As Davey (2013) noted, interactions among colleagues allow for elaboration, digression, and personal expression of feelings. This interaction allows the idea exploration.

Reflection is the process of senior lecturers coming to understand their own practices and those of others better. All of them talk about the difficulties they have faced and mentioned that changes cannot be avoided. Ms. Betty understands that she has choices; taking a leave from teaching because of the lack of technological skills or continuing to teach. All of them have decided to upskill themselves. Mr. Dion explains that it takes a while to accept the change. He even has a mild heart attack during the first few weeks of teaching. Mr. Emmanuel takes time to accept the situation while upskilling himself. He mentions talking to his fellow senior lecturers about the difficulties, where to get help, and others. Ms. Annie reflects that she needs to get more collaborations with her colleagues. Ms. Chandra mentions that virtual communication is not as easy as offline and realizes that the situation is not easy for everyone. Everyone should work extra hard to be able to teach effectively. All of them aware of the existing situation. They have to move out of their comfort zone because not only do they think it is possible to do, but they also realize benefits to be gained from it. They are aware of whatever decisions they have made for continuing to teach during ERT.

Transformation leads to thoughtful changes as the senior lecturers decide to continue teaching through ERT. It is mentioned that Mr. Dion has a mild heart attack due to being anxious about using technology. Ms. Betty explains her continuous fight with her daughters as she is frustrated during the first few meetings. Mr. Emmanuel finds his students in the classroom could not pick up his jokes during teaching because of the bad connections. Besides, he needs extra preparations, especially the asynchronous ones. Ms. Annie also struggles to make students engaged during the ERT. Students' internet connections are also a problem. While she is ready with the interactive teaching plan, some students could not participate fully due to the limited internet connection. Ms. Chandra does not find the first semester (February to July) an easy ride. As she effectively runs the class, she faces some technical problems that frustrated her sometimes. The teaching preparation needs more time for ERT than offline classes. She has to prepare more plans in case some plans do not work. Those are the disruptions of their existing work that cause them to confront their own belief that teaching brings them joy. However, if those disruptions do not happen, the transformation could not be expected. Those disruptions happen multiple times, and those shape them to be more upskilled lecturers.

All of them do not find major problems during the September semester compared to ERT in MarchJuly as the university has a more established ERT system. Those senior lecturers have also been used to the provided system. Having adopted learning mechanisms as a lens to identify senior lecturers' experiences with online teaching during ERT, there are two key findings worthy of further discussion. The first is that learning is unavoidable. The second and final point is how their learning is laid out as it is not instant changes. The first key finding shows that senior lecturers are required to have closer collaboration among lecturers. These inevitable learnings make it essential for them to be well equipped to work effectively in these new conditions and to recognize and manage the challenges that this pandemic brings. The second key finding presents the process of changes that entails stages that works simultaneously. They are as an individual who is learning to teach with technology during the ERT, as a lecturer who has to deliver the materials in the virtual classroom with multichannel teaching, and as a faculty member who has to follow university's directions during the ERT.

Park's (2015) argument is in line with the concept of legitimate peripheral participation that suggests a gradual way in which newcomers enter a community of practice. Their initial participation is peripheral, as it involves acting as an onlooker and performing routine, low-skilled jobs. As learners move from the periphery to the center of participation, they develop their social identity and skills. As they gain 
knowledge of practices, the newcomers eventually become seniors. Senior lecturers are onlookers when they start ERT; however, they have to learn to teach online from the start. Through learning and applying what they learned, they become used to it. Joining various webinars by seeking assistance from colleagues and relatives, they move to the periphery. By the beginning of a new semester, they are ready to teach online again. Shulman (1987) has stated that teaching is, essentially, a learned profession. Thus, learning during teaching is inevitable.

Applying learning mechanisms to identify teachers' learning experiences shows that changes do not happen instantly. It all starts with accepting the fact that the situation changed. They find the gap between what they need to do and their capabilities. They make decisions to change; however, they face some obstacles. They seek various assistance to get them upskilled. Knowledge and skills are reconstructed due to the disruptions they experienced (Bakker \& Akkerman, 2017). As illustrated before, all participants learn about themselves and their practice through the teaching journey. The learning mechanism proposed by Akkerman and Bakker (2017) helps identify and understand how senior lecturers' learning and interactions during ERT. The ability to work effectively among the lecturers during the ERT appears to depend very much on their skills to traverse the sometimes-tricky terrain of different teaching situations. Effective communication among lecturers is essential.

\section{CONCLUSIONS}

Since the Covid-19 breaks in Jakarta in March 2020, the situation forces BINUS University to operate emergency remote teaching (ERT). Delivering content and how to make students engage during ERT are not the only issue of concern; caring and supporting senior lecturers is also imperative. All five senior lecturers in the research have experienced learning, reshaping, and upskilling themselves as lecturers. As they go to unfamiliar territory, they find discrepancies between their capabilities and the needs for ERT. While they face obstacles, they do not take the teaching role itself as an obstacle. With the help of colleagues, relatives, virtual webinars on how to teach online, they are offered the opportunities to learn. They redefine the current situation as an opportunity for learning. Both students and lecturers will remember not the educational content delivered but how they feel during these hard times. With an empathetic approach, the story will not center on delivering educational content successfully, but it will be on how learners and lecturers narrate these times.

Since the participants are chosen purposefully, the research aims neither to display consistency across situations and time periods nor to develop generalizability of the findings. There are several interesting opportunities for future research related to the research. First, as the focus of the research is on senior lecturers' learning mechanisms, other researchers may explore the impact of their learning on students' achievements. Secondly, other researchers may further contribute to the understanding of the complexity of the ERT. Data emerging from the research can also be further analyzed and used to refine future research on senior lecturers.

\section{REFERENCES}

Akkerman, S. F., \& Bakker, A. (2012). Crossing boundaries between school and work during apprenticeships. Vocations and Learning, 5(2), 153-173. https://doi. org/10.1007/s12186-011-9073-6.

Akkerman, S. F., \& Bruining, T. (2016). Multilevel boundary crossing in a professional development school partnership. Journal of the Learning Sciences, 25(2), 240-284. https://doi.org/10.1080/10508406.2016.11 47448.

Akkerman, S. F., \& Van Eijck, M. (2013). Re-theorising the student dialogically across and between boundaries of multiple communities. British Educational Research Journal, 39(1), 60-72. https://doi.org/10.1 080/01411926.2011.613454.

Bakker, A., \& Akkerman, S. F. (2017). The learning potential of boundary crossing in the vocational curriculum. In L. Unwin \& D. Guile (Eds.), Handbook on Vocational Education (pp. 1-19). New Jersey: Wiley.

Batalla-Busquets, J. M., \& Pacheco-Bernal, C. (2013). On-the-job e-learning: Workers' attitudes and perceptions. International Review of Research in Open and Distributed Learning, 14(1), 40-64. https://doi.org/10.19173/irrodl.v14i1.1304.

Braun, V., \& Clarke, V. (2012). Thematic analysis. In H. Cooper, P. M. Camic, D. L. Long, A. T. Panter, D. Rindskopf, \& K. J. Sher (Eds.), APA Handbooks in Psychology, APA handbook of Research Methods in Psychology, Vol. 2, Research Designs: Quantitative, Qualitative, Neuropsychological, and Biological (pp. 57-71). USA: American Psychological Association

Bronkhorst, L. H., \& Akkerman, S. F. (2016). At the boundary of school: Continuity and discontinuity in learning across contexts. Educational Research Review, 19, 18-35. https://doi.org/10.1016/j. edurev.2016.04.001.

Burns, A., Freeman, D., \& Edwards, E. (2015). Theorizing and studying the language-teaching mind: Mapping research on language teacher cognition. The Modern Language Journal, 99(3), 585-601. https://doi. org/10.1111/modl.12245.

Cohen, J. (1960). A coefficient of agreement for nominal scales. Educational and Psychological Measurement, 20(1), 37-46. https://doi.org/10.1177 $\% 2 \mathrm{~F} 001316446002000104$.

Davey, R. (2013). The professional identity of teacher educators: Career on the cusp? London: Routledge.

Fejes, A., \& Köpsén, S. (2014). Vocational teachers' identity formation through boundary crossing. Journal of Education and Work, 27(3), 265-283. https://doi.or 
g/10.1080/13639080.2012.742181.

Fenwick, T. (2016). Professional responsibility and professionalism: A sociomaterial examination. London: Routledge.

Fenwick, T., Edwards, R., \& Sawchuk, P. (2015). Emerging approaches to educational research: Tracing the socio-material. London: Routledge.

Gherardi, S. (2019). How to conduct a practice-based study: Problems and methods. Cheltenham: Edward Elgar Publishing.

Golden, C. (2020). Remote teaching: The glass halffull. Retrieved from https://er.educause.edu/ blogs/2020/3/remote-teaching-the-glass-half-full.

Kersh, N. (2015). Rethinking the learning space at work and beyond: The achievement of agency across the boundaries of work-related spaces and environments. International Review of Education, 61(6), 835-851. https://doi.org/10.1007/s11159-015-9529-2.

Lavine, R., Greenberg, J., Chen, J., Kao, K., \& Lin, Y. T. (2012). East meets west: A virtual international teacher education initiative between Taiwan and the US. Journal of the International Society for Teacher Education, 16(1), 35-45.

McHugh, M. L. (2012). Interrater reliability: The kappa statistic. Biochemia Medica, 22(3), 276-282.

Miles, M. B., Huberman, A. M., \& Saldana, J. (2014). Qualitative data analysis: A methods sourcebook. Los Angeles: SAGE Publications, Inc.

Pamuk, S. (2012). Understanding preservice teachers' technology use through TPACK framework. Journal of Computer Assisted Learning, 28(5), 425-439. https://doi.org/10.1111/j.1365-2729.2011.00447.x.

Park, J. Y. (2015). Student interactivity and teacher participation: An application of legitimate peripheral participation in higher education online learning environments. Technology, Pedagogy and Education, 24(3), 389-406. https://doi.org/10.1080/ 1475939X.2014.935743.

Phelan, P., Davidson, A. L., \& Cao, H. T. (1991). Students' multiple worlds: Negotiating the boundaries of family, peer, and school cultures. Anthropology \& Education Quarterly, 22(3), 224-250. https://doi. org/10.1525/aeq.1991.22.3.05x1051k.

Rosebery, A. S., Ogonowski, M., DiSchino, M., \& Warren, B. (2010). The coat traps all your body heat: Heterogeneity as fundamental to learning. Journal of the Learning Sciences, 19(3), 322-357. https:// doi.org/10.1080/10508406.2010.491752.

Shulman, L. S. (1987). Knowledge and teaching: Foundations of the new reform. Harvard Educational Review, 57(1), 1-23. https://doi.org/10.17763/ haer.57.1.j463w79r56455411.

Tsai, H. C. (2015). A senior teacher's implementation of technology integration. International Education Studies, 8(6), 151-161. https://doi.org/10.5539/ies. v8n6p151.

Tuomi-Grohn, T., \& Engestrom, Y. (2003). Between school and work: New perspectives on transfer and boundary crossing. Abingdon: Taylor \& Francis.

UNESCO. (2020). COVID-19 educational disruption and response. Retrieved from https://en.unesco. org/news/covid-19-educational-disruption-andresponse.

Veltman, M. E., Van Keulen, J., \& Voogt, J. M. (2019). Design principles for addressing wicked problems through boundary crossing in higher professional education. Journal of Education and Work, 32(2), 135-155. https://doi.org/10.1080/13639080.2019.1 610165 . 